\title{
Rita Chaves: marinheira de muitas viagens
}

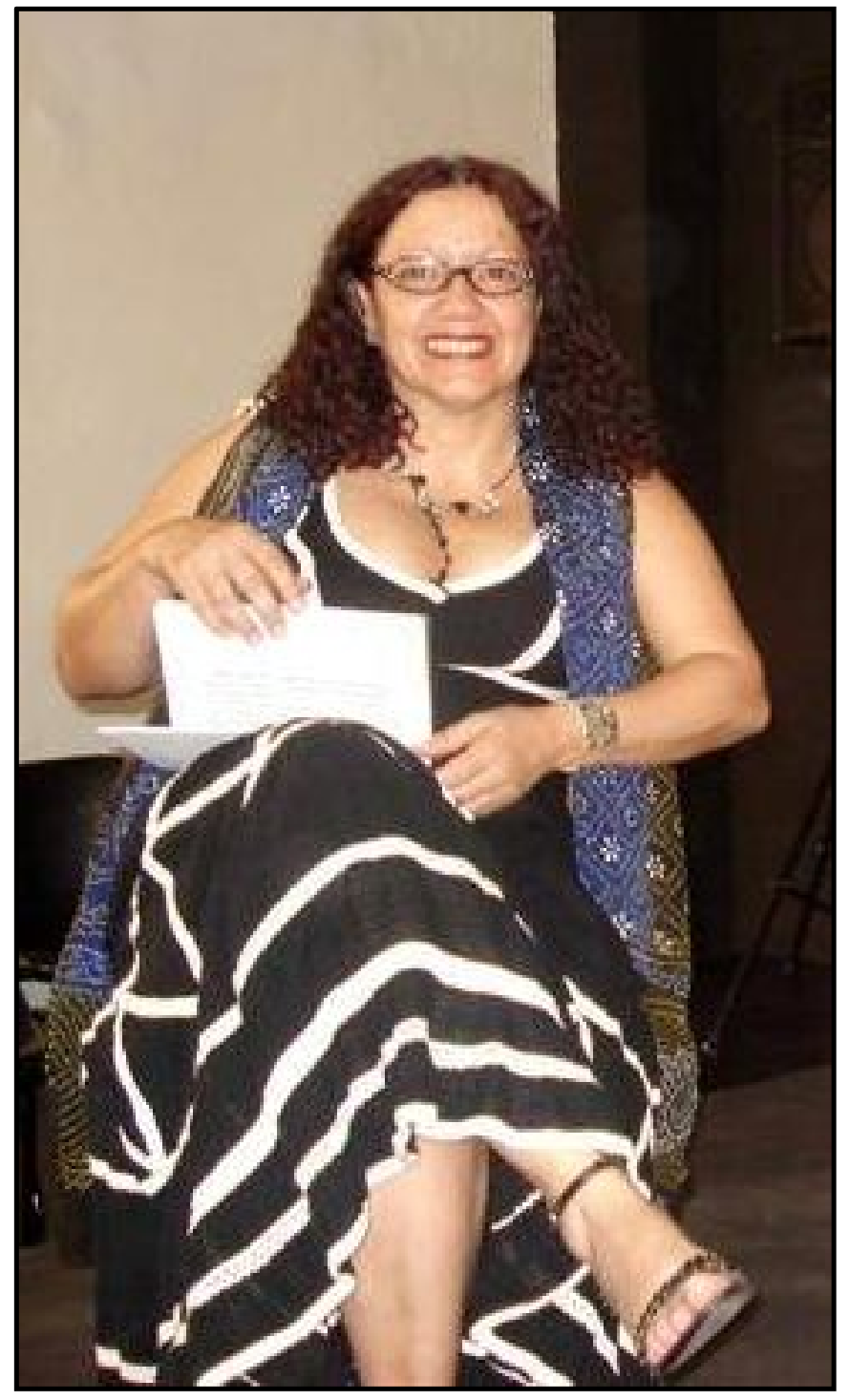

Foto: Genivaldo Rodrigues Sobrinho

\author{
Mara Regina Paulino ${ }^{1}$ \\ Débora David ${ }^{2}$
}

"No mar da vida, não há caminho, mas estrelas que orientam..."

Benjamin Abdala Júnior

A sala de aula fica pequena para conter o entusiasmo e a paixão de suas histórias que enlevam a todos. Deste exíguo espaço seus ouvintes são levados para novos horizontes, para margens distantes que rapidamente se transformam de território desconhecido a um espaço-tempo claro e próximo, como se estivesse bem aqui desde sempre. Do seu percurso por territórios angolanos, cabo-verdianos e moçambicanos, Rita Chaves nos trouxe a perspectiva necessária para a compreensão de outros universos, outras culturas e tradições; conhecimentos que não se transmitem sem a dose necessária da humilde consciência de que o campo das literaturas africanas de língua portuguesa demanda uma marcha incansável e sem fim. 
Suas aulas, ensaios e palestras trazem relatos tão intensos e verdadeiros sobre o outro lado do Atlântico, que impelem a audiência ao conhecimento deste mundo que é ao mesmo tempo distante e próximo de nossa história e cultura. É a partir dessa perspectiva de pesquisa e ensino que Rita Chaves apresenta-se uma intelectual que, emprestando palavras de Edward W. Said, consegue transmitir, dar corpo e articular uma mensagem para e por um público no âmbito das literaturas africanas de língua portuguesa.

Trata-se, sobretudo, de uma investigadora que mesmo realizando o seu mister por meio de uma árdua tarefa, diria Appiah, “consegue avaliar a vida e as pretensões de outras culturas e tradições sem se tornar presa dos preconceitos decorrentes de perspectivas unilaterais". E assim, com a devida sensibilidade intelectual pela cosmologia africana, desenvolvida pelas muitas idas e vindas transatlânticas, Rita Chaves tem aproximado, ano após ano, alunos, professores e estudiosos em geral a essa parte essencial do conjunto das literaturas de língua portuguesa.

Rita de Cássia Natal Chaves graduou-se em Letras pela Universidade Federal Fluminense em 1978 no Rio de Janeiro. Se o interesse pela Literatura teve início ainda nos bancos escolares, foi na graduação que as literaturas africanas de língua portuguesa entraram em sua vida pelas mãos da Profa. Dra. Vilma Arêas. Defendeu seu mestrado em 1984, ainda pela Universidade Federal Fluminense. Em 1993, doutorou-se em Letras pela Universidade de São Paulo, realizando uma importante investigação sobre o romance angolano ( $A$ formação do romance angolano: entre intenções e gestos), em cuja banca examinadora participou especialmente o mestre Antonio Candido, de quem é discípula confessa. Além de um pós-doutorado concluído em 2001 pela Universidade Eduardo Mondlane (Moçambique), atuou ainda como docente visitante em várias Universidades, inclusive no exterior. Atualmente é docente de Literaturas Africanas de Língua Portuguesa na Universidade de São Paulo (USP) e responsável pela disciplina 
Literatura e Colonização da Universidade Cândido Mendes, no Rio de Janeiro.

O incansável trabalho de Rita Chaves em prol da literatura e cultura africana é expresso também pela publicação de obras que fomentam a pesquisa e contribuem para a formação do público-leitor brasileiro. Por exemplo, em 2002, junto com Tania Macêdo, ela organizou a publicação, em Angola, da primorosa bibliografia Portanto... Pepetela, obra de referência sobre um dos ícones da literatura angolana, a qual felizmente será publicada no Brasil em breve. Em 2005, com Tania Macêdo e Inocência Mata foi a vez de outro angolano, Boaventura Cardoso, receber a merecida atenção à sua vida e obra em Boaventura Cardoso: a escrita em processo (São Paulo: Alameda/UEA). Esses inestimáveis trabalhos, junto com muitos outros que a estudiosa certamente planeja, compõem o grande painel da fortuna crítica que tem consolidado as literaturas africanas entre nós.

Na produção científica de Rita Chaves destacam-se ainda: $A$ formação do romance angolano: entre intenções e gestos (São Paulo, 1999), com prefácio de Pepetela; Angola e Moçambique: o lugar das diferenças nas identidades em processo (Rio de Janeiro, 2001); Angola e Moçambique - experiência colonial e territórios literários (Cotia, 2005). Além disso, organizou inúmeros livros de artigos em parceria com docentes da USP e de outras universidades brasileiras e do exterior. Citamos algumas: Brasil/África: como se o mar fosse mentira (São Paulo/Luanda, 2006); Marcas da diferença (São Paulo, 2006); A kinda e a misanga - encontros brasileiros com a literatura angolana (São Paulo, 2007).

Professora e pesquisadora que abraçou a árdua missão de desmistificar o imaginário literário e cultural dos países africanos de língua portuguesa, especialmente Angola e Moçambique, vem reafirmando que ainda se quisesse não seria possível uma análise das produções literárias e, por extensão, destes países meramente nos moldes europeus. Destacamos aqui as palavras do professor moçambicano Lourenço do Rosário de que "nenhuma abordagem sobre 
a problemática da natureza de nossas literaturas pode pretender-se objetiva sem ter em conta os instrumentos de reflexão teórica que a Rita [Chaves] nos coloca no momento".

As explanações de Rita Chaves são as da viajante e pesquisadora que no percurso de suas andanças busca sentido e formas do mundo literário e cultural que se produz nos países africanos de língua oficial portuguesa, e muitas outras. Neste caso podemos pensar no que Osman Lins apresenta no seu livro Marinheiro de Primeira viagem quando este escreve que "o verdadeiro viajante/narrador é aquele que reflete um espírito ligado ao destino dos seus semelhantes, que acredita no homem e na literatura, e ao interessar pelos problemas dos outros países e consequentemente de outros povos demonstra o carinho e o verdadeiro interesse pelo "Outro" de forma mais verídica. Sua viagem atual pelos escritos do angolano Ruy Duarte de Carvalho confirma a fala acima e aponta a íntima relação entre a Literatura, a Antropologia e a História como componentes extremamente relevantes para uma análise literária mais coerente das sociedades que se firmaram diante do prisma de culturas diversas.

Precisaríamos de muitas e muitas páginas para falar de todo o conhecimento que a mestra acumulou ao longo de sua carreira, e dos laços de experiência e amizade que cultiva, além dos autores aqui referidos, com Luandino Vieira, Mia Couto, Ondjaki, Nelson Saúte e tantos outros da mais velha e mais nova geração de autores africanos que enriquecem as literaturas de língua portuguesa. Ao compartilhar o seu conhecimento, Rita Chaves converte-se na estrela que nos orienta pelo imenso mar da vida acadêmica, estreitando as margens atlânticas e índicas para que possamos atravessar com segurança e seriedade o caminho das literaturas africanas de língua portuguesa no Brasil.

1 Mestranda em Estudos Comparados de Literaturas de Língua Portuguesa (FFLCH-USP). Bolsista CNPq.

${ }^{2}$ Doutoranda em Estudos Comparados de Literaturas de Língua Portuguesa (FFLCH-USP). Bolsista CNPq. 